\title{
Entrevista: Prof. Dra. Isabela Benseñor
}

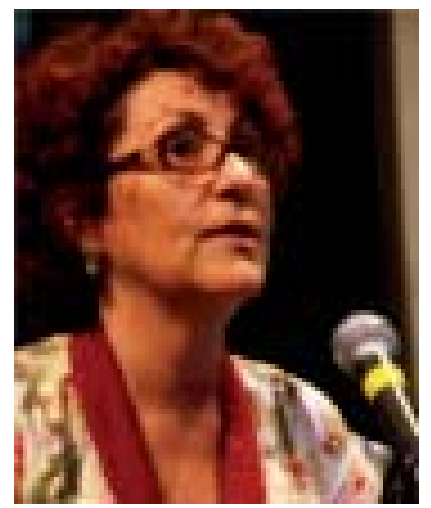

Formada em Medicina pela Faculdade de Medicina da USP em 1982, Residência em Clínica Médica 1983-85, e Pós-doutorado em Epidemiologia pela Harvard Medical School em 1997, a Prof. Dra. Isabela Benseñor é hoje um dos maiores nomes da Epidemiologia e da Clínica Médica no país. Professora livre docente da Faculdade de Medicina da USP dedica-se fortemente ao ensino e à pesquisa, sem, entretanto, desprivilegiar a prestação de serviço médico a população.

\section{RM: O que fez a senhora se interessar por clínica médica enquanto estava na faculdade?}

Prof. Dra. Isabela Benseñor: Até o fim do quarto ano, eu tinha muita dúvida sobre o que eu queria fazer. A minha "panela" começou o internato pela clínica médica e em dois meses eu já tive certeza do que eu queria. Então fiz um ano de residência - naquela época não havia dois anos de clinica geral antes de ir para especialidade - e eu tinha que escolher entre ir para especialização ou ficar na clínica geral. Eu escolhi ficar na geral porque nunca consegui me decidir sobre uma especialidade específica, eu gostava de tudo, gostava de hematologia, de nefrologia, de endocrinologia. Mas eu acho que um dos fatores que influencia muito na escolha da residência é o local por onde você começa o internato.

Há estudantes que já sabem o que vão fazer desde o primeiro ano. Mas uma dica que eu acho importante para as pessoas que vão escolher sua especialidade é que elas tentem entender como elas funcionam, por exemplo, tem pessoas que não se importam de dar plantão, de trabalhar, à noite... é o aluno que pode ser anestesista, ou trabalhar numa UTI. Tem gente que não gosta de trabalhar a noite, em absoluto. Essas pessoas têm que escolher especialidades em que elas não vão dar plantão, que tenham um horário mais horizontal. Eu acho que o aluno tem que entender isso, que numa determinada fase da vida não adianta ele gostar, ele ter a ilusão do que aquela especialidade é, ele tem que pensar se ele é uma pessoa que gosta de levar a rotina de vida que aquela especialidade impõe e se, daqui a cinco, dez anos, ele vai conseguir viver essa mesma rotina. Às vezes você tem alguma idéia romântica sobre a especialidade, e às vezes a realidade é mais dura do que se imagina e você vai ter que se encaixar nela. Isso é um ponto importante. Eu falo sempre na tutoria: vejam do que vocês gostam e o que vocês conseguem fazer.

RM: A senhora acredita que está ocorrendo, atualmente, uma especialização precoce do aluno de medicina?

Prof. Dra. Isabela Benseñor: O que determina muitas coisas é o mercado. O mercado às vezes paga mais para o especialista. Por outro lado estamos num movimento para formar médicos que vejam o paciente 
como um todo. Isso não quer dizer que tem que ser um clínico geral. É freqüente ouvir que: "o médico da atenção básica é melhor porque vê o doente como um todo". Qualquer médico bom tem que ver o doente como um todo. Você não pode ter aquela visão ultra especializada e só se concentrar no que você está tratando. Mas eu acho que existe realmente uma atração pelas coisas heróicas como neurocirurgia ou cirurgia cardíaca. Eu lembro que meu pai me disse uma vez: mas porque você não vai ser neurocirurgiã? (risos). Isso nem passava pela minha cabeça. Mas a visão que ele tinha de fora era uma visão romântica do que ele achava que era medicina. A gente tem que ter cuidado com essas coisas. A atenção básica é extremamente importante, a clínica geral também é importante, as especialidades são importantes... e, é importante que você enxergue seu doente dentro desse esquema usando todos os recursos disponíveis.

RM: Há na Universidade uma cobrança sobre os docentes para que eles tenham constantes publicações científicas. Isso é algo que pode prejudicar o ensino? Há, realmente, a necessidade de se exigir que o docente, além de se dedicar a ensinar, se dedique à pesquisa?

Prof. Dra. Isabela Benseñor: Eu acho que a universidade tem que ter pessoas que trabalhem com ensino e com pesquisa. Ela também precisa formar pessoas para assistência. $O$ que às vezes se exige é que uma pessoa faça todas as coisas e eu acho que esse é o erro. Na universidade devem existir pessoas que vão trabalhar mais com o ensino, porque é o que elas gostam e serão ótimos professores e deve haver pessoas que vão trabalhar com pesquisa, o que também é muito importante. Eu, durante muito tempo, tive uma vida equilibrada entre ensino, pesquisa e assistência médica, depois de um tempo eu tive que cortar a assistência (eu ainda tenho um ambulatório, mas eu tive que cortar porque as outras coisas já não davam espaço). Durante algum tempo eu organizei vários projetos na atenção primaria e aí acabei ficando com muito material de pesquisa aguardando publicação, porque é impossível fazer todas as coisas ao mesmo tempo. Então agora eu parei um pouco e estou tentando tocar meus projetos que estavam atrasados. Agora, é complicada essa pressão que existe sobre o professor. Ele não consegue fazer tudo bem o tempo todo. Tem momentos em que você vai fazer mais uma coisa ou mais outra. Dentro de um departamento é preciso ter gente que ensina e gente que pesquisa, não necessariamente a mesma pessoa precisa fazer as duas coisas. Eu acho que formar alunos, e não só publicar um monte de papers, é algo que libera muitas endorfinas. É legal você ter, depois, pessoas, que você formou, trabaIhando com você. Hoje eu tenho, trabalhando comigo no Estudo Longitudinal de Saúde do Adulto (ELSA), um aluno meu de iniciação científica de 1995. A chefe de Clínica do ELSA foi minha aluna de propedêutica também em 1995 e agora mais uma ex-aluna se juntou à equipe. O ELSA é um projeto que é muito mais para os meus alunos de agora do que para mim. Se ele durar uns 60 anos, daqui um tempo vocês serão mais pesquisadores ELSA do que eu.

\section{RM: E o que é exatamente o projeto ELSA?}

Prof. Dra. Isabela Benseñor: O ELSA (Estudo Longitudinal de Saúde do Adulto) é um estudo de coorte, um estudo de seguimento, a primeira coorte de adultos realmente organizada desde o começo aqui no Brasil com finalidade específica de estudar as doenças cardiovasculares e o diabetes. É um projeto grande, do Ministério da Saúde, com um financiamento de 23 milhões de reais e que é dividido em seis centros. São Paulo é um dos centros e tem um terço do estudo. No momento, estamos colhendo os dados da linha de base. É um questionário muito grande sobre os fatores de risco clássicos e com muitas informações sobre onde a pessoa vive, o que se chama de variáveis de contexto: se o lugar onde ela mora é um lugar violento, se é um lugar onde ela tem acesso a alimentos frescos, se ela pode fazer caminhadas, etc. Nós vamos estudar muito essa questão de onde a pessoa mora e vamos avaliar também alguns exames específicos, vamos colher sangue para fazer aqueles exames clássicos (colesterol, triglicérides, etc.), um teste de tolerância à glicose (para o diagnóstico de diabetes), etc. Então vamos estudar colesterol, proteínas ultra-sensíveis, alguns fatores de inflamação. Vamos avaliar o eletrocardiograma, ecocardiograma, ultrassonografia em que vamos avaliar a espessura da média/íntima das carótidas (para ver obstrução), esteatose no fígado, e espessura do panículo adiposo da gordura pré-peritoneal para ver obesidade. Faremos algumas medidas de fisiologia como a velocidade de onda de pulso, que na verdade avalia a distensibilidade de aorta e que vai nos permitir estudar o início do processo arterosclerótico. Fazemos também a variabilidade da freqüência cardíaca, para estudar o tônus do simpático/parasimpático pois já se sabe hoje em dia que pessoas que apresentam uma oscilação maior entre simpático e parassimpático tem mais risco cardiovascular. Fazemos o ITB (índice tornozelo-braquial), que avalia doença vascular periférica e temos um questionário muito grande para avaliar vários fatores psicossociais e transtornos 
psiquiátricos, o que é importante, pois sabemos hoje que a depressão é um fator de risco para doenças cardiovasculares. Estamos estudando, também, toda essa relação das doenças psiquiátricas como fatores de risco.

Um entrevistador nosso vai até o local de trabalho da pessoa, para fazer uma parte do questionário e depois a pessoa vem um dia aqui no $\mathrm{HU}$ e fica 6 horas fazendo todos os exames e respondendo a uma outra parte do questionário e depois nós vamos seguir essa pessoa ao longo do tempo para ver o que acontece com ela, para ver se ocorre algum desfecho. No início serão desfechos intermediários como ganho de peso, etc. Depois serão desfechos mais relacionados a doenças cardiovasculares e diabetes e depois vamos observar ocorrência de câncer... , mas isso demanda mais tempo de estudo.

\section{RM: E o ELSA tem uma previsão de durar quanto tempo?}

Prof. Dra. Isabela Benseñor: Temos um financiamento inicial para os primeiros 5 anos, mas já foi aprovado um segundo financiamento de 10 milhões justamente para poder avaliar essas pessoas novamente daqui a 3 anos. Então acho que até os próximos 6, 7 anos estão garantidos. Mas aí é uma questão de você ir conseguindo mais financiamentos. $O$ estudo de Framingham nos Estados Unidos (uma cidade próxima a Boston) fez 60 anos e já estamos com a terceira geração de pesquisadores), os participantes iniciais também já morreram (estão sendo estudados agora os filhos dos participantes iniciais) e vocês vêem pelo escore de Framingham que este estudo continua trazendo informações muito importantes. Agora, é fundamental que nós conheçamos as coisas como elas acontecem no nosso país, porque a distribuição dos fatores de risco aqui é diferente. Então nós precisamos poder um dia calcular o nosso próprio escore e não usar um escore de uma classificação americana, baseada numa população que tem características diferentes da população brasileira.

\section{R.M.: E quais são as principais diferenças entre o ELSA e o estudo de Framingham?}

Prof. Dra. Isabella Benseñor: O ELSA é um estudo maior (Framingham tinha 5.700 participantes e nós teremos 15.000). Framingham se preocupou muito com os exames de sangue, ou seja, toda essa parte de transtornos psiquiátricos, outros fatores psicossociais como qualidade de vida e as variáveis de contextos não faziam parte. Outro ponto importante é que no ELSA temos um questionário de freqüência alimentar, a gente criou esse questionário novo, adaptado às várias regiões do Brasil (o ELSA não inclui a região Centro-Oeste e a Região Norte, num primeiro momento, mas temos o compromisso de formar pesquisadores para estender a pesquisa para essas duas regiões) e com isso talvez possamos ter informações super importantes relacionadas à dieta. Nós sabemos, por exemplo, em termos de mortalidade cardiovascular que Belém é a capital com a menor mortalidade cardiovascular, o que provavelmente tem a ver com o que se come lá (muito peixe). Poderemos, portanto, comparar a alimentação da Bahia com a do Rio Grande do Sul e avaliar o quanto isso influencia a mortalidade cardiovascular nessas pessoas que estão sendo seguidas. Há também uma preocupação de se levantar dados inéditos, pois não adianta apenas repetir o que os outros já fizeram, então estamos estudando a doença aterosclerótica em uma fase mais jovem (a partir dos 35 anos), para que possamos responder alguma coisa sobre o início do processo aterosclerótico.

\section{RM: E quais seriam as principais aplicações práticas dos resultados do ELSA?}

Prof. Dra. Isabela Benseñor: Eu acho que é avaliar, no nosso país, o que é realmente um fator de risco importante e o peso dos fatores de risco. Por exemplo, avaliar onde a pessoa vive e o quanto isso influencia nas questões de saúde é super importante. Temos também uma escala que mede capital social, ou seja, se essa pessoa conhece alguém que, por exemplo, fale uma outra língua, ou se conhece alguém que possa dar um conselho em termos de mercado financeiro, etc. É uma questão de medir um pouco as relações dentro da sociedade. Às vezes você não é uma pessoa rica, mas você tem uma rede de apoio dentro da sua vida que facilita para você alcançar alguns objetivos. Então a gente está medindo muito essas coisas que são importantes e que ninguém mediu num país como o Brasil, que tem uma série de contrastes. Das coortes grandes do Hemisfério Sul, o ELSA é a maior e vai trazer outras informações importantes, por exemplo, a influência da exposição solar sobre a saúde. É muito diferente aqui, no hemisfério sul, onde as pessoas são mais expostas ao sol do que no hemisfério norte, onde você tem as terras habitáveis muito próximas aos pólos e com isso você vai avaliar particularidades do metabolismo do cálcio, da vitamina $D$, como ele é no hemisfério sul e comparar com o hemisfério norte. Às vezes nós usamos pontos de corte na densitometria óssea que são adequados para o hemisfério norte, mas não para o hemisfério sul.

RM: A senhora fez seu pós-doutorado em Boston. Qual a importância de ter uma formação no Brasil e 
no exterior? O Brasil hoje tem condições de fornecer uma estrutura científica sólida?

Prof. Dra. Isabela Benseñor: Para mim e para o Lotufo, foi muito importante ter ido para fora. Fiz o meu doutorado tarde porque eu casei, tive meus filhos, trabalhei no HU e saí porque não queria dar mais plantão, fiquei 7 anos trabalhando na Prefeitura e depois é que eu voltei para o HC, em 1994, e terminei meu doutorado, em 1997. Eu acho que esse é um primeiro conselho, dá para você fazer as duas coisas na vida, mas não no mesmo momento, então às vezes você cuida mais dos seus filhos, depois você volta a fazer pesquisa ou para um lugar mais acadêmico, mas não quer dizer que você tem que desistir disso. Para nós foi extremamente importante ficar em Boston e conhecer o dia a dia de um grande estudo de epidemiologia. Eu trabalhei no Women's Health Study e, ele no Physician's Health. Trabalhar dentro de um grande estudo de coorte foi muito importante para saber exatamente o que eu teria que fazer no dia em que eu montasse o meu próprio estudo, então foi extremamente importante. Outra coisa que é importante às vezes é você, quando sai, conhecer outras pessoas, como uma outra sociedade vive ou se comporta. Eu fiquei nos EUA na era Clinton (1992-2000), a economia a toda, altíssimo astral, agora uma aluna minha, que voltou recentemente, foi para o mesmo lugar onde eu fiquei, já na era Bush (2001-2008), foi muito mais difícil, desde a papelada que pediam, tinha que comprovar muito mais coisas agora do que na minha época. Eles nunca pediram diploma, se eu era médico ou não era médico, se eu tinha ou não tinha doutorado, eu falei que eu era médica, tinha doutorado e eles aceitaram nunca ninguém pediu, mas hoje em dia é mais complicado. É muito interessante viver lá, entender como eles se comportam como eles levam o trabalho, é extremamente interessante e desmistifica algumas coisas. O brasileiro trabalha muito mais horas que 0 americano, nos EUA, tudo é o "nine to five", das 9h às $17 \mathrm{~h}$, aqui nós trabalhamos muito mais e fazendo mais coisas, às vezes em função de falta de estrutura. Mesmo assim, foi muito importante. Independente da área em que você esteja não precisa ser a Medicina, é muito importante passar um tempo fora, você aprende a organizar a sua vida de outro jeito, você entra em contato com pessoas que depois vão ser pontes, você pode pensar um estudo aqui que tem um parceiro nos outros lugares. Às vezes você, nem que seja durante o curso, vai lá por 6 meses, vai fazer uma Iniciação Científica lá, você não está perdendo tempo, está ganhando experiência, aprendendo técnicas, a conviver com outras pessoas, de outras culturas. Isso foi extremamente importante também para os meus filhos, foi uma coisa que marcou a vida deles. $O$ inglês é uma língua que, hoje, você tem que falar, e, quanto mais cedo você vai, mais você aprende. A desgraça é que depois seus filhos são cidadãos do mundo, então eles vão embora (risos), você os exporta o que também é terrível, formar uma pessoa aqui no Brasil e depois exportar, como está acontecendo em muitas áreas. O Brasil investiu nessa pessoa e, depois, ela vai para fora, e você perde. É legal ficar um tempo, mas é legal voltar, nunca passou pela nossa cabeça não voltar porque nós somos brasileiros, as coisas que você gosta estão aqui. Além disso, se você quiser ser médico de verdade lá, vai ter que fazer Medicina outra vez e fazer residência lá, o que é uma perspectiva péssima, mas, se quiser ser pesquisador tudo bem... Eu, por exemplo, não queria essa coisa de não ter mais contato com o aluno, não poder atender alguém, isso para mim iria tirar um pedaço, então nunca passou pela nossa cabeça não voltar. Atualmente, a CAPES (Coordenação de Aperfeiçoamento de Pessoa de Nível Superior) e a CNPq (Comissão Nacional de Desenvolvimento Científico e Tecnológico) financiam o doutorado e o pós-doutorado fora, mas a FAPESP (Fundação de Amparo à Pesquisa do Estado de São Paulo) só faz por 5 meses, o que eu acho ruim, pois a FAPESP hoje só estimula os pós-doutorados aqui no Brasil. Para algumas coisas, nós temos aqui total expertise para que elas façam seu pósdoutorado, mas para o estudo epidemiológico, foi muito importante ter ido para fora. Existem outros coortes aqui no Brasil, principalmente de crianças como as de Pelotas, e de idosos como o coorte de Bambuí, mas são coortes menores e que não seguem o modelo do coorte de Framingham. E, quando nós voltamos, a idéia era montar um estudo de coorte aqui. Nós voltamos aqui em dezembro de 1999, tentamos vários financiamentos em várias fundações fora e dentro do Brasil, e a primeira reunião do ELSA aconteceu durante a Olimpíada de Atenas (2004). Em dois anos e meio, foi aprovado todo o processo no ministério, o dinheiro saiu e a nós começamos o campo nas Olimpíadas da China (2008). Ou seja, desde a primeira reunião para escrever o projeto, foram 4 anos, é um investimento de tempo muito grande. Desde que eu voltei dos EUA demorou 5 anos até nós montarmos o grupo que coordena 0 ELSA e mais 4 anos para o campo se iniciar, então são coisas que envolvem muito tempo.

RM: A senhora falou que muitas pessoas decidem fazer uma coisa fora. A senhora acha que falta alguma coisa aqui no Brasil, algum elemento, alguma falta de apoio... 
Prof. Dra. Isabela Benseñor: Eu acho que, em algumas áreas, sim, mas as pessoas têm que tentar mudar as coisas aqui para que você possa conseguir o que você pretende. Às vezes você não deve desanimar, não deve achar que, aqui, não há condições, tem que batalhar por elas, porque nunca se financiou no Brasil tanta pesquisa como agora, foram milhares de editais que saíram neste ano, então existe uma nova visão do Brasil em relação à pesquisa. Acho que a questão é você se organizar e criar um grupo de trabalho forte e você conseguir fazer as suas coisas aqui também. Às vezes você precisa ir para fora para aprender algumas coisas e voltar, o governo tem financiado muita pesquisa, saíram 4 projetos do INCT aqui na FMUSP que agrega pesquisas de muitíssima qualidade. Creio que, às vezes, é importante você ir para fora aprender alguma coisa, quando você vai para fora tem uma diferença importante: você só faz aquilo, não atende ninguém, não dá aula, então você fica mergulhado naquele universo, isso ajuda, você lê muita coisa, e então fica mais maduro, mas é importante que as pessoas voltem e que tentem montar projetos aqui, que elas não desistam, há condições atualmente de fazer pesquisa. Muitas vezes você vai ter que formar o pesquisador, não é que nem nos Estados Unidos, em Boston, onde o college forma gerentes de pesquisa. Aqui no ELSA, tivemos a experiência de trabalhar com pessoas que não tinham experiência e formálas como assistentes de pesquisa, e a experiência tem sido ótima. A nossa gerente de pesquisa é uma mestranda da Geografia, que aprendeu tudo e hoje é extremamente competente, desde para coisas burocráticas, como importar alguma coisa, até coisas mais práticas, do dia-a-dia de um projeto de pesquisa, de uma coorte. Temos 50 estagiários e 20 bolsistas do CNPq, no total 70 pessoas trabalhando no ELSA em São Paulo. É uma experiência muito boa investir em um aluno que está começando e transformá-lo em um pesquisador. Tem também essa questão do aluno de medicina, que apesar da enorme carga horária do curso, também poder ao menos uma vez por semana freqüentar um grande projeto de pesquisa epidemiológica, um estudo de coorte.

\section{RM: Nos EUA, os alunos de medicina fazem 4 anos de College e só vão entrar em contato com o paciente após este período...}

Prof. Dra. Isabela Benseñor: Eles começar a ter contato mesmo com o paciente no terceiro ou quarto ano da faculdade de medicina, ou seja, o sétimo ou oitavo ano do curso. Por exemplo, uma vez o meu filho, lá em Boston, teve um problema, e nós tivemos que levá-lo para a emergência do Children's
Inn. Quem o atendeu foi uma aluna do $4^{\circ}$ ano da Medicina, em um modelo muito parecido com o AGD (Ambulatório Geral e Didático do Hospital das Clínicas da FMUSP), ou seja, ela veio, tirou a história, saiu, discutiu com o professor, voltou com o professor, que checou algumas coisas do que ela tinha feito. Eles explicam, "olha, eu sou um aluno, eu vou atender o seu filho", como nós fazemos aqui também no HC ou no HU, mas lá existe muito mais recusa em ser atendido pelo aluno, então ao fazer a faculdade de medicina aqui você entra em contato com um número maior de pacientes do que se fizesse lá. Aqui no $\mathrm{HC}$ ou no HU o paciente gosta de ser atendido pelo aluno, porque ele demora mais, tem mais tempo para conversar, então você acaba vendo muito mais paciente aqui e aprende muito mais do ponto de vista prático. Lá, aquela história de o aluno conversar com um ator é muito forte porque lá há uma restrição muito maior ao aluno atender pacientes, tanto nos EUA como na Europa, enquanto que aqui temos pouca recusa. Então, em termos práticos nossos alunos terão contato com mais pacientes aqui no Brasil do que lá, quanto a isso não há a menor dúvida e isso, no final das contas, tem um peso muito importante. Muito bem, lá na Harvard tem uma salinha para cada aluno, cada um tem o seu computador, aqui temos salas pró-aluno que são usadas por todos, mas aqui vocês verão mais pacientes, o que é muito rico. Especificamente aqui na FMUSP, vocês vão ver que o aluno sai com uma visão muito boa da prática, sabe fazer uma prescrição, tem uma visão muito mais prática, não é aquele que só ficou no livro lendo, e isso é muito importante, e disso vocês não devem abrir mão, da parte prática, dos hospitais, que dão uma vivência muito especial, você às vezes não vai conseguir em outros lugares.

RM: A senhora acha que esse maior contato com o paciente aqui no Brasil interfere na visão humanística do aluno, na relação médicopaciente?

Prof. Dra. Isabela Benseñor: Acho que sim, aqui no Brasil você dá um "tapinha nas costas", abraça, pergunta como vão os filhos. Lá o médico assim "há uma chance de 33\% de você ter isso ou aquilo", lá o relacionamento é muito mais frio, muito mais impessoal, e falo isso como usuária do sistema de saúde americano. Você espera horas para ser atendido e a consulta é muito mais seca e menos rica do que a Propedêutica Clínica do segundo e terceiro anos, acho que não se compara.

RM: A idade média dos alunos que ingressam na Faculdade tem sido cada vez menor, muita 
gente entra cada vez mais cedo, alunos com 17,16 anos. De que forma isso afeta, se afeta, a educação médica?

Prof. Dra. Isabela Benseñor: Isso já vem acontecendo há muito tempo. Na minha sala, havia uma pessoa com 16 anos que, na época, teve que impetrar um mandado, apesar dela já ter terminado o ensino médio, pois, na época, não se admitia isso. Acho que o aluno não tem que ter pressa em se formar. Nós não temos como mudar o fato dele entrar cedo, mas ele não deve ter pressa de terminar em seis anos. Por exemplo, se ele achar um estágio de seis meses fora, ele deve fazer e voltar, ele não está perdendo um ano, ele está ganhando experiência. Eu acho que o aluno deve experimentar muita coisa na faculdade, para ele testar o que ele quer. A medicina oferece muitas possibilidades, você pode ser médico, pesquisador, administrador, você pode não se encaixar numa área, mas se encaixar em outra. Também se deve, dentro do possível, aproveitar a vida, ter outras coisas fora, porque você não pode ficar apenas pensando e discutindo coisas médicas, tem que ter algum hobby, alguma coisa importante para você fazer. Se você gosta de cinema, curta o cinema; se gosta de ler livros, leia livros; se gosta de viajar, viaje, o que você puder, porque são coisas importantes até para formar o aluno como pessoa, e aí você vai ser um médico melhor. As pessoas não devem entrar na faculdade e largar tudo o que elas gostam, tem que deixar uma porta aberta para o que elas gostam, as mais variadas possíveis, cinema, astronomia, o que for, atividades que, nos momentos de tensão, funcionam como relaxantes, que são gostosa, que permite conhecer pessoas diferentes também. $O$ aluno não deve se preocupar em fazer certinho os seis anos, o que é muito da medicina, pois outras faculdades aqui da USP não fazem necessariamente. Os alunos da FAU (Faculdade de Arquitetura e Urbanismo), por exemplo, param, fazem um estágio, voltam depois, fazem intercâmbio, eles não se formam em cinco anos, formam em seis, sete. Às vezes o aluno da medicina pode fazer as coisas mais devagar, curtindo mais. Se quiser fazer um estágio fora, faça, volte, veja como é que é, mesmo coisas não ligadas à medicina. Em alguns momentos isso ajuda como válvula de escape para a tensão, de vez em quando pensar em uma coisa diferente do que ser médico, mas que, de uma certa maneira, vai ajudar a formar um médico melhor. Acho que você tem que vivenciar bastante a faculdade, mas fazer uma coisa fora que lhe dê um horizonte diferente, e também não se preocupar em fazer os seis anos certinhos, às vezes parar seis meses não é o fim do mundo, a formação é longa, depois vem à residência, então você pode parar em seis meses e mergulhar em algo que lhe interesse, desde atender em algum lugar ou um projeto de laboratório ou algo diferente, mais cultural. Você tem o resto da vida para fazer um monte de coisas, mas aproveitar esta parte para curtir um pouco.

\section{RM: Neste ano será lançado o "Tratado de Clínica Médica", escrito pelos professores da Faculdade. Qual a importância de se ter um Tratado de Clínica Médica de peso feito no Brasil em comparação a outras obras clássicas importadas, como o Cecil ou o Harrison?}

Prof. Dra. Isabela Benseñor: Eu acho que ter livros brasileiros é importante para trabalhar com a epidemiologia das doenças daqui, com um toque brasileiro, porque a epidemiologia aqui tem características próprias do Brasil. Às vezes um Cecil não está voltado para estas questões, embora este ano eles vão lançar um Cecil com um Box brasileiro, do qual eu participei (também escrevi alguns capítulos do Tratado de Clínica Médica). O que é importante é saber que, no Brasil, temos estudos que avaliam os nossos dados. É péssimo quando você começa uma aula falando que "nos Estados Unidos...". Ora, pode falar dos Estados Unidos, mas tem que falar também como é no Brasil. O DATASUS, a Fundação Seade, a Prefeitura têm um monte de dados e é importante que se trabalhe com eles. Temos que citar a prevalência de doença cardiovascular como ela é no Brasil, com suas características próprias. É importante que exista esta diferenciação sobre como são as coisas no Brasil. Existem muitos dados bons, é questão de você ir atrás, se você entrar no MedLine vai ver um monte de artigos no Brasil, como é o AVC no Brasil, como é a doença cardiovascular no Brasil.

\section{RM: A senhora gostaria de dizer mais alguma coisa para os alunos?}

Prof. Dra. Isabela Benseñor: Nós trabalhamos aqui no ELSA com estagiários de Graduação (50, atualmente) que em geral estudam a noite e recebem uma bolsa de estágio durante o dia. É ruim que no ELSA não possam se encaixar alunos da Faculdade de Medicina, porque vocês têm aula o tempo todo. Mas a nossa idéia para esse ano é trazer alunos de iniciação científica, para que eles possam saber como é trabalhar num grande estudo, como é em qualquer outro lugar do mundo. Então aproveito a oportunidade para convidar os alunos a participar do ELSA, quem quiser e tiver um horário em que queira fazer um estágio de iniciação à pesquisa aqui. Os alunos da medicina e da USP, que tem cursos integrais, não conseguem participar de um projeto 
como o ELSA em que a pessoa tem que estar aqui todo dia, das 8 às 14h. Eu acho uma incoerência o fato de esse projeto acontecer dentro da Medicina e ter poucos alunos da Medicina envolvidos. Então nossa idéia é fazer um convite geral a quem quiser fazer sua iniciação científica aqui no ELSA, principalmente alunos de $1^{\circ}$ e $2^{\circ}$ anos, que estão aqui na Cidade Universitária.
O ELSA é muito clínico, é uma Iniciação Científica que não é em um laboratório, em que você interage com pessoas. É uma experiência muito interessante fazer um estudo aqui na USP, onde você tem particularidades, vem o docente, o jardineiro, 0 técnico... Incrível como ocorrem milhões de coisas dentro da USP que a gente não percebe por ficar trancado na sua própria Unidade.

\section{NOTA:}

Mais informações sobre o ELSA podem ser obtidas no site do projeto: www.elsa.org.br A pedido da Prof. Dra. Isabela Benseñor, disponibilizamos aqui seu e-mail para os alunos que se interessarem em conhecer e participar do Projeto ELSA. isabensenor@ hu.usp.br 